\title{
Large-scale ice-sheet modelling as a means of dating deep ice cores in Greenland
}

\author{
Ralf Greve \\ Department of Mechanics, Technische Hochschule Darmstadt, D-64289 Darmstadt, Germany
}

\begin{abstract}
The three-dimensional ice-sheet model SICOPOLIS is used to simulate the dynamic/thermodynamic behaviour of the entire Greenland ice sheet from 250000 a BP until today. External forcing consists of a surface-temperature history constructed from $\delta^{18} \mathrm{O}$ data of the GRIP core, a snowfall history coupled linearly to that of the surface temperature, a piecewise linear sea-level scenario and a constant geothermal heat flux. The simulated Greenland ice sheet is investigated in the vicinity of Summit, the position where the maximum elevation is taken, and where the two drill sites GRIP and GISP2 are situated $28 \mathrm{~km}$ apart from each other. In this region, the agreement between modelled and observed topography and ice temperature turns out to be very good. Computed age-depth profiles for GRIP and GISP2 are presented, which can be used to complete the dating of these cores in the deeper regions where annual-layer counting is not possible. However, artificial diffusion influences the computed ages in a near-basal boundary layer of approximately $15 \%$ of the ice thickness, so that the age at the bottom of the cores cannot be predicted yet.
\end{abstract}

\section{INTRODUCTION}

The deep ice cores GRIP and GISP2, which were drilled close to the highest point of the Greenland ice sheet ("Summit”) at $72^{\circ} 34^{\prime} \mathrm{N}, 37^{\circ} 38^{\prime} \mathrm{W}$, contain direct and indirect information on palacoclimatic conditions such as atmospheric composition, surface temperature, snowfall rate, reaching back at least 250000 years into the past (Dansgaard and others, 1993; Sowers and others, 1993; Meese and others, 1994). In order to obtain time series of these climatic parameters, it is necessary to provide age depth profiles of the boreholes. This can be achieved partly by counting annual layers downward; however, in the lower parts of ice cores, annual layers cannot be resolved (Johnsen and others, 1992; Meese and others, 1994). Therefore, flow models must be used to compute age depth profiles from the point where annual layers cease to be resolvable down to the bottom of the ice sheet.

Here, the three-dimensional transient large-scale icesheet model SICOPOLIS (Greve, 1995, 1997) is applied to the Greenland ice sheet and a simulation is presented which covers 250000 years of climate history. It is shown that the present state of the ice sheet in the vicinity of Summit is reproduced very well and that the simulation provides reasonable age depth profiles except for the very near-bottom regions.

\section{THE MODEL SICOPOLIS}

SICOPOLIS ("SImulation COde for POLythermal Ice Sheets") is a three-dimensional dynamic/thermodynamic ice-sheet model which simulates the time-dependent extent, thickness, velocity, temperature, water content and age for any specified grounded ice sheet as a response to external forcing. External forcing is given by (i) surface temperature, (ii) snowfall rate, (iii) sea level surrounding the ice sheet, and (iv) geothermal heat flux from below.

In this study, SICOPOLIS is applied to the Greenland ice sheet, and a palaeoclimatic simulation which covers the period from $250 \mathrm{ka}$ BP (here, BP refers to thousand calendar years before present) until today, is discussed. The simulation is driven by the mean annual air-temperature $\left(T_{\mathrm{ma}}\right)$ reconstruction derived from the $\delta^{18} \mathrm{O}$ profile of the GRIP core (Dansgaard and others, 1993) and the conversion formula (Johnsen and others, 1995)

$$
T_{\mathrm{ma}}=\alpha+\beta \delta^{18} \mathrm{O}+\gamma\left(\delta^{18} \mathrm{O}\right)^{2},
$$

with $\alpha=-211.4^{\circ} \mathrm{C}, \beta=-11.88^{\circ} \mathrm{C} \times(\text { per mil })^{-1}$ and $\gamma=$ $-0.1925^{\circ} \mathrm{C} \times(\text { per mil })^{-2}$ (Fig. 1). This relation is established back to marine-isotope stage $5 \mathrm{~d}, 113 \mathrm{ka} \mathrm{BP}$; however, in this study, it is used to compute a surface-temperature history for the entire $250 \mathrm{ka}$ covered by the $\delta^{18} \mathrm{O}$ data. Before $113 \mathrm{kaBP}$, the so-obtained surface-temperature history is smoothed by 2000 year averaging and used as a reasonable initialization of the simulation. The impact of the uncertainty level of Equation (1) on the ice sheet can be judged by comparing computed and measured borehole temperature profiles. The discussion below (section 3 ) shows that the discrepancy is less than $2{ }^{\circ} \mathrm{C}$ throughout the boreholes GRIP and GISP2. The effect of these slight deviations on the ice fluidity due to the thermomechanical coupling is negligible when compared to uncertainties in the ice rheology itself (dust content, anisotropy).

The snowfall rate $S$, the temporal evolution of which has a pronounced effect on computed age depth profiles, is coupled linearly to the air-temperature deviation $\Delta T_{\mathrm{ma}}=$ $T_{\mathrm{ma}}-T_{\mathrm{ma}}^{\text {today }}$

$$
S=S^{\text {today }} \times\left(1+\gamma_{\mathrm{s}} \Delta T_{\mathrm{ma}}\right),
$$

with $\gamma_{\mathrm{s}}=0.03^{\circ} \mathrm{C}^{-1}$, corresponding to a $75 \%$ reduction of $S$ 


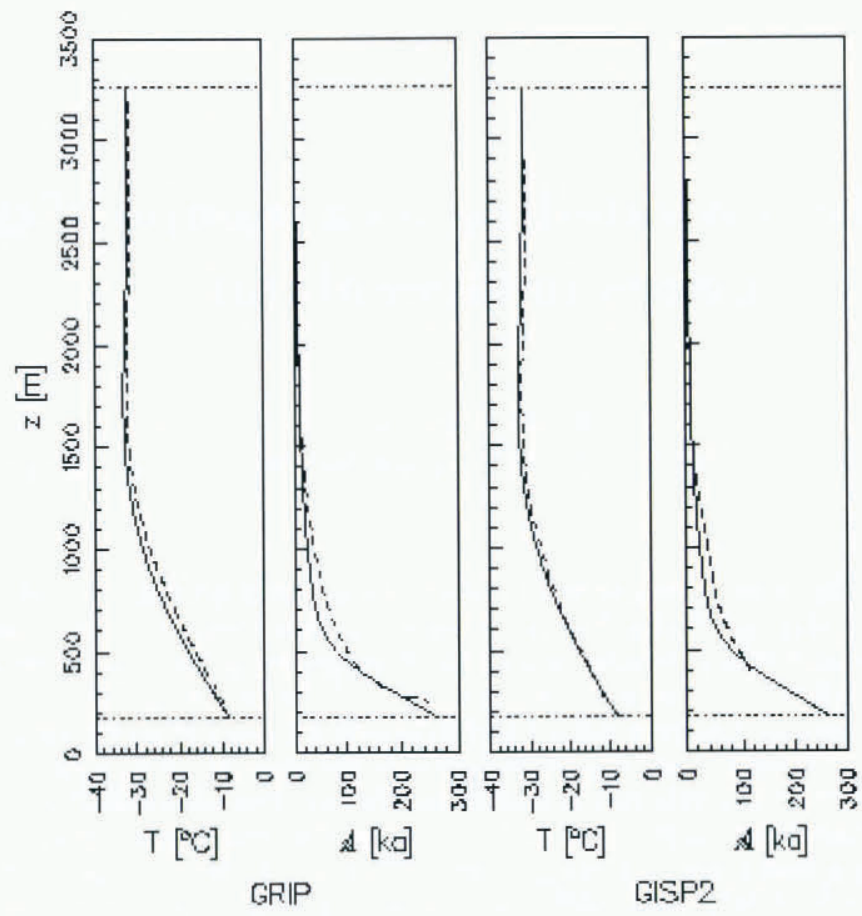

Fig. 1. Air-temperature forcing $\Delta T_{\mathrm{ma}}$, sea-level forcing $z_{\mathrm{sl}}$, ice thicknesses $H$ at GRIP (solid) and GISP2 (dash-dotted), basal temperatures $T_{\mathrm{b}}$ al GRIP (solid) and GISP2 (dash-dolted).

for glacial conditions, specified by $\Delta T_{\text {ma }}=-25^{\circ} \mathrm{C}$ (cf. Cuffey and others, 1995; Cutler and others, 1995). Certainly, this is a simplified approach. In reality, the existence of a unique relation between $S$ and $\Delta T_{\text {ma }}$, or, equivalently, between $S$ and $\delta^{18} \mathrm{O}$ is not granted, and spatial variabilities in changes of $S$ are excluded completely in Equation (2). In future work, it should therefore be aimed at replacing simple parameterizations like Equation (2) by more detailed information obtained by climate modelling (e.g. Ohmura and others, 1996).

For the sea-level, $z_{\text {sl }}$, which only affects the ice-sheet margin to some extent and is not crucial for the temporal evolution of the ice sheet in central Greenland, a piecewise linear scenario is applied (Fig. 1), which represents a simple approximation of current reconstructions (e.g. SPECMAP record, Imbrie and others (1984); New Guinea record, Chappell and Shackleton (1986)). For the geothermal effects, a temperature-gradient boundary condition is imposed $5 \mathrm{~km}$ below the ice base to account for thermal inertia of the lithosphere and the geothermal heat flux is kept constant at $Q_{\text {geoth }}^{\perp}=65 \mathrm{~mW} \mathrm{~m}^{-2}$.

Horizontal grid spacing is $20 \mathrm{~km}$. The vertical resolution is 51 grid points in the cold-ice region, 11 grid points in the temperate-ice region (if existing) and 11 grid points in the lithosphere. Emphasis is put on a $160 \times 160 \mathrm{~km}$ window around Summit where high-resolution radio-ccho-sounding data of the ice-surface and bedrock topography are available (Hodge and others, 1990) and where the GRIP and GISP2 drill sites are located.

\section{RESULTS}

In addition to the external forcing of $\Delta T_{\mathrm{ma}}$ and $z_{\mathrm{s}}$, Figure 1 shows the simulated temporal evolution of the ice thicknesses $H$ at GRIP and at GISP2, $H_{\text {GRIP }}$ and $H_{\mathrm{GISP} 2}$, respectively, and the temporal evolution of the basal temperatures $T_{\mathrm{b}}$ at GRIP and GISP2, $T_{\mathrm{GRIP}}$ and $T_{\mathrm{GISP} 2}$, respectively. The thicknesses follow the air-temperature forcing in phase, because central Greenland is virtually not affected by ablation but reacts most sensitively to changes of the snowfall rate which is larger during warm climates (see Equation (2)). The agreement between modelled and observed present ice thicknesses is very good. The predicted GRIP column is $61 \mathrm{~m}$ thicker than observed $(3090 \mathrm{~m}$ instead of $3029 \mathrm{~m}$ ) and the predicted GISP2 column is $32 \mathrm{~m}$ thicker than observed ( $3076 \mathrm{~m}$ instead of $3044 \mathrm{~m}$ ).

The basal temperatures do not change by more than $3{ }^{\circ} \mathrm{C}$ during the simulation, even though the air temperatures vary by $27.7^{\circ} \mathrm{C}$. This is due to the impact of the large ice thicknesses in the Summit region, which strongly dampen surface oscillations. Surprisingly, $T_{\mathrm{GRIP}}$ and $T_{\mathrm{GISP} 2}$ are low during the warm Eemian and their values at the Last Glacial Maximum 21 ka BP exceed today's values. Cooler basal temperature during interglacial climates is expected because ice velocity is larger, and this enhances advection of cold surface ice towards the base. The counteracting effect of enhanced strain heating is not relevant close to ice domes, consequently the advection effect is dominant and warm climates entail low basal temperatures around Summit (and vice versa). Again, the agreement for the present values is very good: the predicted value for $T_{\mathrm{GRIP}}$ is $-8.35^{\circ} \mathrm{C}$ as compared to a measured value of $-8.56^{\circ} \mathrm{C}$ for GRIP. The measured value for GISP2 is not yet published, so comparison with the $-7.90^{\circ} \mathrm{C}$ predicted value is not yet possible.

In Figure 2 the measured (Hodge and others, 1990) and simulated present surface topographies and ice thicknesses in the vicinity of Summit are presented. The shape of the surface topography is reproduced very well, the most conspicuous discrepancy being the region above $3200 \mathrm{~m}$ elevation, which is distinctly too large. Nevertheless, the difference between simulated and measured elevations nowhere exceeds $80 \mathrm{~m}$ and is approximately $30 \mathrm{~m}$ at GRIP and GISP2. The distance between the simulated and actual summit position is $12.3 \mathrm{~km}$. Better agreement is not possible 

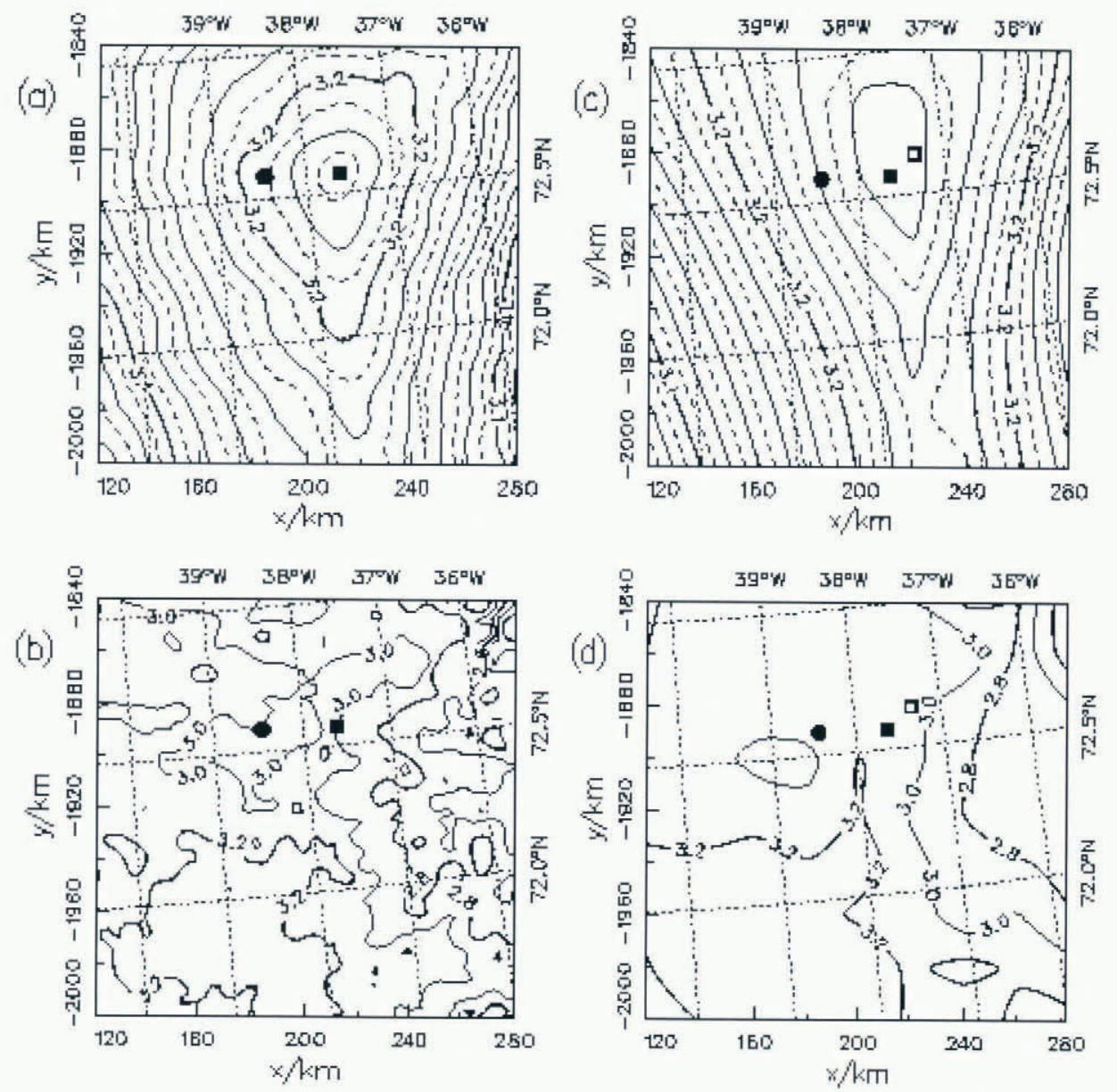

Fig. 2. The present vicinity of Summit. (a) Measured surface topography (Hodge and others, 1990), (b) measured ice thickness (Hodge and others, 1990), (c) simulated surface topography, (d) simulated ice thickness. Solid squares show the GRIP position, solid circles the GISP2 position and open squares the position of the simulated summil (only in panels c and d). Surface elevations in $\mathrm{km}$ a.s.l. (spacing $10 \mathrm{~m}$ ), ice thicknesses in $\mathrm{km}$ (spacing $200 \mathrm{~m}$ ).

because of the $20 \mathrm{~km}$ grid resolution. The agreement for the ice-thickness distribution is equally convincing. Even though the fine structure of the data ( $2 \mathrm{~km}$ resolution) cannot be reproduced by the $20 \mathrm{~km}$ grid, the main features (the almost closed $3200 \mathrm{~m}$ contour in the southwest, the $2800 \mathrm{~m}$ contour in the east, the general decrease towards the northeast) are very well predicted.

Figure 3 depicts the computed present temperature and age profiles at GRIP and GISP2, and compares them with the measured temperature profiles (Cuffey and others, 1995; Johnsen and others, 1995) and previous datings (Dansgaard and others, 1993; Sowers and others, 1993; Meese and others, 1994), respectively. The agreement for the two temperature profiles is very good, the distinct improvement compared to Greve and others (in press) (the slight temperature inversion was not reproduced in that study) being due to the different $\delta^{18} \mathrm{O}-$ to- $T_{\text {ma }}$ conversion with lower glacial air temperatures applied here (see Equation (1)). The computed age-depth profiles are in almost perfect agreement with the observed datings in the upper parts of the two ice cores where the latter were determined from annual-layer counting. In contrast, below $2000 \mathrm{~m}$ depth, the simulation predicts ice up to $35 \%$ younger compared to the datings by Dansgaard and others (1993), Sowers and others (1993) and Meese and others (1994), which is apparently a consequence of the fully three-dimensional transient modelling applied here.

Below $2500 \mathrm{~m}$ depth, however, the solution scheme for the age equation makes the predicted age depth results im-

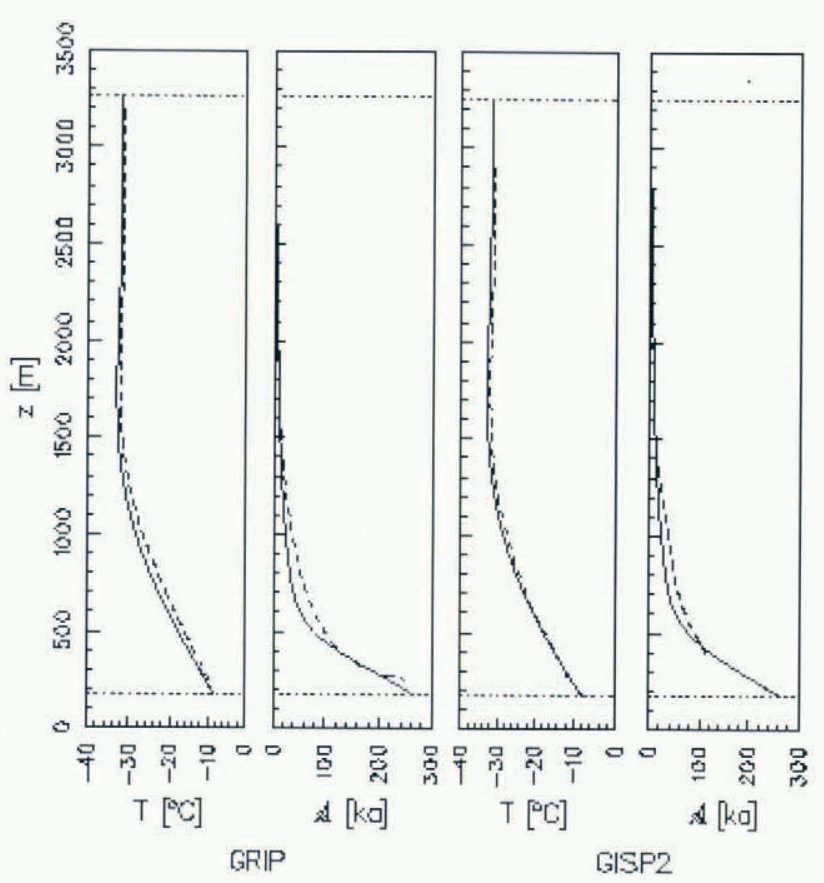

Fig. 3. Simulated temperature-depth and age depth profiles for GRIP and GISP2 (solid), measured temperature depth profiles (Cuffey and others, 1995; Johnsen and others, 1995) (dashed), previous age depth profiles (Dansgaard and others, 1993; Sowers and others, 1993; Meese and others, 1994) (dashed). 
precise for the following reason. The age field $\mathcal{A}$ is calculated by

$$
\frac{\mathrm{d} \mathcal{A}}{\mathrm{d} t}=1 \quad\left(+D_{\mathrm{A}} \frac{\partial^{2} \mathcal{A}}{\partial z^{2}}\right)
$$

where $\mathrm{d} / \mathrm{d} t$ implies the material time derivative which incorporates ice movement. The bracketed term in Equation (3) is a purely artificial vertical diffusion which is required for numerical stability. The value of the diffusivity $D_{\mathrm{A}}$, $D_{\mathrm{A}}=5 \times 10^{-8} \mathrm{~m}^{2} \mathrm{~s}^{-1}$, is chosen to be as small as possible but large enough to ensure stable integration. Thus, an artificial boundary condition at the ice base, $z=b(x, y, t)$, is required:

$$
\left.\frac{\partial \mathcal{A}}{\partial z}\right|_{z=b}=-m_{\text {age }} \cdot \frac{1}{S_{\text {mean }}}
$$

where $m_{\text {age }}$ is the thinning factor, chosen as $m_{\text {age }}=200$ and $S_{\text {mean }}$ is the mean snowfall rate on the ice sheet (for further discussion see Greve and others (in press)). By choosing a typical ice thickness $[H]=3000 \mathrm{~m}$ and a typical vertical velocity $\left[V_{\mathrm{H}}\right]=0.1 \mathrm{~m} \mathrm{a}^{-1}$, the time-scale for advection is

$$
t_{\mathrm{adv}}=[H] /\left[V_{\mathrm{H}}\right]=3 \times 10^{4} \mathrm{a}
$$

and the time-scale for (artificial) diffusion is

$$
t_{\text {diff }}=[H]^{2} / D_{\mathrm{A}}=5.7 \times 10^{6} \mathrm{a} .
$$

Obviously, $t_{\mathrm{diff}} \gg t_{\mathrm{adv}}$, so that the influence of the artificial diffusion term on the computed age depth profiles is negligible except for a basal boundary layer where the results depend on the artificial boundary condition (4). By conducting additional simulations with $m_{\text {age }}=0$, Greve and others (in press) demonstrated that the thickness of this boundary layer is approximately $15 \%$ of the total ice thickness in the Summit region of the Greenland ice sheet, which corresponds to the lowest $500 \mathrm{~m}$ of the GRIP and GISP2 cores.

\section{CONCLUSION}

This study demonstrates that the large-scale ice-sheet model SICOPOLIS, when driven by a realistic palaeoclimatic scenario of air temperature, snowfall rate and sea level, reproduces the present state of the Summit region of the Greenland ice sheet very well. This good reproduction justifies using the model as a means of computing age-depth profiles for the deep parts of the GRIP and GISP2 ice cores where annual-layer counting is not possible. Hereby, the main shortcoming is the necessity of including numerical diffusion in the age calculation, which makes the results in a near-bottom boundary layer unreliable. Future work must consequently aim at avoiding this by either adopting a more stable discretization scheme for the purely advective age Equation (3) or by applying a direct particle-tracing algorithm.

\section{ACKNOWLEDGEMENTS}

The author wishes to thank Dipl.-Phys. M. Weis for aid in improving the computer program and laying out the plots, Professor K. Hutter for helpful comments on the manuscript, Professor D. R. MacAyeal for a careful and constructive review, Dr S. Johnsen for the temperature profile at GRIP, Dr A. Letréguilly and Dr S. Hodge for the topographic data of Greenland. The support of this work by the Deutsche Forschungsgemeinschaft is gratefully acknowledged.

\section{REFERENCES}

Chappell, J. and N. J. Shackleton. 1986. Oxygen isotopes and sea level. Nature, 324 (6093), 137-140.

Cuffey, K. M., G. D. Clow, R. B. Alley, M. Stuiver, E. D. Waddington and R.W. Saltus. 1995. Large Arctic temperature change at the Wisconsin Holocene glacial transition. Science, 270 (5235), 455-458.

Cutler, N. N., C. F. Raymond, E. D. Waddington, D. A. Meese and R. B. Alley. 1995. The effect of ice-sheet thickness change on the accumulation history inferred from GISP2 layer thicknesses. Ann. Glaciol., 21, 26-32.

Dansgaard,W. and 10 others, 1993. Evidence for general instability of past climate from a 250-kyr ice-core record. Nature, 364 6434), 218220.

Greve, R. 1995. Thermomechanisches Verhalten polythermer Eisschilde Theorie, Analytik, Numerik. Ph.D. thesis, Technische Hochschule, Darmstadt.)

Greve, R. 1997. A continuum-mechanical formulation for shallow polythermal ice sheets. Philos. Trans. R. Soc. London, A355, 921-974.

Greve, R., M. Weis and K. Hutter. In press. Palaeoclimatic evolution and present conditions of the Greenland ice sheet in the vicinity of Summit: an approach by large-scale modelling. Paleoclimates.

Hodge, S. M., D. L. Wright, J. A. Bradley, R.W. Jacobel, N. Skou and B. Vaughn. 1990. Determination of the surface and bed topography in central Greenland. J. Glaciol., 36 (122), 17-30.

Imbrie, J. and 8 others. 1984. The orbital theory of Pleistocene climate: support from a revised chronology of the marine $\delta^{18} \mathrm{O}$ record. In Berger, A., J. Imbrie, J. Hays, G. Kukla and B. Saltzman, eds. Milankovitch and climate: understanding the response to astronomical forcing. Part 1. Dordrecht, etc., D. Reidel Publishing Co., 269-305. (NATO ASI Series C: Mathematical and Physical Sciences 126.

Johnsen, S. J. and 9 others. 1992. Irregular glacial interstadials recorded in a new Greenland ice core. Nature, 359 6393), 311-313.

Johnsen, S. J., D. Dahl-Jensen, W. Dansgaard and N. S. Gundestrup. 1995. Greenland paleotemperatures derived from GRIP borehole temperature and ice core isotope profiles. Tellus, 47B (5), 624-629.

Meese, D. A. and 8 others. 1994. Preliminary depth-age scale of the GISP2 ice core. CRREL Spec. Rep., 94-1.

Ohmura, A., M. Wild and L. Bengtsson. 1996. Present and future mass balance of the ice sheets simulated with GCM. Ann. Glaciol., 23, 187-193.

Sowers, T. and 7 others. 1993. A 135,000-year Vostok-SPECMAP common temporal framework. Paleoceanography, 8(6), 737-766. 